\title{
COVID-19 contamination of high-touch surfaces in the public domain
}

\author{
Niall T. Hennessy ${ }^{1,2} \cdot$ Sinead Toomey ${ }^{2}\left(\right.$ Virginie Gautier $^{3} \cdot$ Sophie O'Reilly $^{3} \cdot$ Eoghan de Barra $^{4} \cdot$ Emer O. Hanrahan $^{5}$. \\ Bryan T. Hennessy ${ }^{2}$
}

Received: 29 November 2021 / Accepted: 30 November 2021 / Published online: 10 January 2022

(c) The Author(s), under exclusive licence to Royal Academy of Medicine in Ireland 2021

The virus that causes COVID-19 disease (SARS-CoV2) is a major global threat to public health, with mortality and serious morbidity rates of up to 5 and $15 \%$, respectively [1, 2]. It is also very damaging to the global economy. The virus can be transmitted by airborne spread or by direct contact with contaminated surfaces $[3,4]$. It is thus crucial to determine if high-touch public surfaces are contaminated. This could have important public health implications by identifying contaminated surfaces and reinforcing the important public health messages regarding hand hygiene, especially in children. In this project, we focused on playground equipment in public spaces, public toilet surfaces and buttons at pedestrian crossings throughout Dublin because these are high-touch public surfaces that may contribute to the spread of the virus.

During the third wave of the COVID-19 pandemic in Dublin, between January 19 and February 23, 2021, we swabbed (1) 86 traffic light buttons at pedestrian crossings, (2) 55 touch surfaces on equipment in 5 public playgrounds, and (3) 69 touch surfaces in 6 public toilets of 5 large shopping centres. Specifically with regard to public playground equipment surfaces, we swabbed 12 see-saw handles, 7

Emer Hanrahan and Bryan T. Hennessy contributed equally

Sinead Toomey

sineadtoomey@rcsi.ie

1 St. Andrew's College, Booterstown Ave, Blackrock, Dublin, Ireland

2 Department of Molecular Medicine, RCSI University of Medicine and Health Sciences, Beaumont Hospital, Smurfit Building, Dublin 9, Ireland

3 UCD Centre for Experimental Pathogen Host Research (CEPHR), School of Medicine, Belfield, University College Dublin, Dublin 4, Ireland

4 Department of International Health and Tropical Medicine, Royal College of Surgeons in Ireland, Dublin, Ireland

5 Department of Medical Oncology, St Vincent's University Hospital, Dublin, Ireland spinner handles, 17 climbing handles, 12 swing handles, 1 slide handle, 4 monkey bars, and 2 outdoor 4 -in-a-row games. With regard to the public toilets, we swabbed 20 door handles, 12 toilet flushers, 7 taps, 4 toilet door locks, 1 touch bin lid, 16 toilets (seats, lids and frames), 7 soap dispensers and 2 disability bars.

Using a separate sterile collection swab and viral transport media (Noblebio, Korea) for each surface, we thoroughly rubbed the surface with the swab, returned the swab to viral transport medium and documented each swab for the surface tested. Once collected, the swabs were tested for the presence of SARS-CoV2-VIRAL RNA by polymerase chain reaction (RT-PCR). RT-PCR for the N and ORF1ab genes was performed using a Viasure SARS-CoV-2 RealTime PCR detection kit (CerTest Biotec, Spain). Assays were performed on the Applied Biosystems 7500 Fast instrument (Applied Biosystems, MA, USA). Samples were deemed positive for SARS-CoV-2 if both genes tested or the ORF1ab gene alone tested positive, according to manufacturer's instructions.

Of the 210 surfaces, $3(1.4 \%)$ were positive for the presence of SARS-COV2-VIRAL RNA. Two (2.3\%) were traffic light buttons and $1(1.8 \%)$ was a playground swing handle (Table 1). Samples were considered positive if the $\mathrm{Ct}$ value obtained was less than 38 . Samples were considered negative if there was no amplification signal for the ORF1ab or $\mathrm{N}$ genes, but the extraction control was positive.

The 3 positive samples were sent to the UCD Centre for Experimental Pathogen Host Research for viral culture and tested for SARS-CoV2 infectiousness using VERO E6-TMPRSS2 cells (obtained from the Centre For AIDS Reagents (CFAR), National Institute for Biological Standards and Control (NIBSC)) [5]. Every $24 \mathrm{~h}$ post-exposure, cells were scored under the microscope for the appearance of cytopathic effects (CPEs). When CPEs were observed, or after $92 \mathrm{~h}$ post-exposure, cell-free supernatant was collected and subjected to viral load quantification by RT-qPCR with the QuantiTect Probe RT-PCR Kit (QIAGEN, Hilden, Germany) on the QuantStudio 5 Real-Time PCR system 
Table 1 Surfaces positive for SARS-COV2

\begin{tabular}{llll}
\hline Sample code & Area swabbed & $\begin{array}{l}\text { Ct value } \\
\text { ORF1ab } \\
\text { gene }\end{array}$ & Ct value N gene \\
\hline $4 \mathrm{SH} 3$ & Playground handle & 33.780 & 32.068 \\
13.1 & Traffic light button & 24.611 & Undetermined \\
21.1 & Traffic light button & 21.314 & 18.546 \\
\hline
\end{tabular}

(Applied Biosystems, MA, USA). However, live virus did not culture from any of the samples.

This study clearly shows the potential for SARS-CoV2 viral contamination of frequently touched surfaces in the public domain, and thereby for contaminated surfaces to cause further spread of infection. The lack of contamination of any surface in the public toilets tested is reassuring and probably testament to frequent cleaning of the surfaces by shopping centre staff. Although we did not culture live virus from the three contaminated public services that tested positive for SARS-CoV2 viral RNA by qPCR in this study, it is reasonable to speculate that live virus was present on these surfaces at some point prior to our study.

Author contribution NH collected samples and analysed results. ST extracted viral RNA and performed PCRs for SARS-CoV-2. VG and SOR performed the SARS-CoV2 infectiousness assays. EDB provided advice on study design and analysed the data. $\mathrm{NH}, \mathrm{EH}$ and BH conceived of the need for this study, designed the project, collected samples and analysed data. NH, ST and BH wrote and edited the manuscript. All authors read and approved the final manuscript.
Funding This work was supported by the North East Cancer Research and Education Trust (NECRET) and a Science Foundation Ireland COVID rapid response grant (20/COV/0109).

\section{Declarations}

Ethics approval Ethics approval has not been required for this study.

Consent to participate N/A.

Consent for publication The authors consent to the publication of this article.

Conflict of interest The authors declare no competing interests.

\section{References}

1. Baud D, Xialong Q et al (2020) Real estimates of mortality following COVID-19 infection. Lancet Infect Dis 20(7):773

2. Weerahandi H, Hochman KA, Simon E et al (2021) Post-discharge health status and symptoms in patients with severe COVID-19. J Gen Intern Med 36(3):738-745

3. Zhang R, Li Y, Zhang AL et al (2020) Identifying airborne transmission as the dominant route for the spread of COVID-19. Proc Natl Acad Sci USA 117(26):14857-14863

4. Chia PY, Coleman KK, Tan YK et al (2020) Detection of air and surface contamination by SARS-CoV-2 in hospital rooms of infected patients. Nat Commun 11:2800

5. Matsuyama S, Nao N, Shirato K et al (2020) Enhanced isolation of SARS-CoV-2 by TMPRSS2-expressing cells. Proc Natl Acad Sci U S A 117(13):7001-7003

Publisher's Note Springer Nature remains neutral with regard to jurisdictional claims in published maps and institutional affiliations. 